\title{
CORRELATION ANALYSIS BETWEEN VEGETATION INDEX (NDVI) AND CANOPY COVERAGE (TOC) BASED ON REMOTE SENSING BY USING UAV
}

\author{
Simone Pascuzzi, Francesco Santoro, Alexandros Sotirios Anifantis, Vincenzo Cimino \\ University of Bari Aldo Moro, Italy \\ simone.pascuzzi@uniba.it, francesco.santoro@uniba.it, alexandrossotirios.anifantis@uniba.it, \\ vincenzo.cimino3@gmail.com
}

\begin{abstract}
Remote sensing in precision agriculture that is achieved by using Unmanned Aerial Vehicles (UAV) allows us to measure both the plant vigour and the water stress effect on the vegetation. It is possible to survey wide areas in relatively short times (e.g., $5-10 \mathrm{~min} / \mathrm{ha}$ ) with a ground resolution of $40 \mathrm{~mm} /$ pixel (GSD). Ground Instantaneous Field of View (GIFoV) areas are collected and rendered to prescription maps (tiling and 2D orthorectification): these show the overall condition of the crops and highlight the areas subjected to water or nutritional stress. Identification of the water stressed areas allows the technician/operator to assess the spatial variability of the crop (simple ratio) first, and then conducting field interventions/experiments, such as fertilization plans, weeding, parasite/pathogen management strategies and so on. The aim of this paper is to study the maize crop health condition by means of the remote sensing technique using UAV through the study of the relation between NDVI and TOC. Remote sensing performed at the time (18/06/2018) led to the acquisition of the basic photograms used for building prescription maps meaningful to the agronomic evaluation of the crop condition and progress. The canopy reflectance data (NDVI) of the maize crop were statistically analysed via the Student's t-test. Although the agronomic inputs were uniformly distributed, including the strict genetic basis of the hybrid used, we can infer that such spatial variability is ascribable to the physic-chemical characteristics of the soil, its texture and, possibly, a surfeit of carbonates that compromises the availability of nutrients.
\end{abstract}

Keywords: remote sensing, UAV, vegetation index, maize crop.

\section{Introduction}

Precision agriculture represents the set of the information systems and of the geospatial techniques mediated by sensors (GIS, remote sensing, GPS) useful for measuring and analysing spatial and temporal variability of soil and crop conditions [1-3] and could be useful also in solving some problems related to agricultural activities ranging from the operators' health and safety $[4 ; 5]$, and environment protection [6;7].

Application of corrective strategies allows attenuation of this variability and improvement of the production systems from a technical, environmental and economic point of view [8-10]. Using more controls on inputs and dynamically managing corrective actions during cultivation means improving the process efficiency, using fewer energy resources (fertilizers, plant protection products, irrigation volumes, and so on) [11;12]. There is a strong link between precision agriculture and the process sustainability as well as the reduction of environmental impact. As it is known, remote sensing in precision agriculture allows to obtain, at distance, data concerning the soil or vegetation, or both combined [13]. By adopting multispectral, hyperspectral or thermal optical sensors on drone platforms, it is possible to measure the reflectance and the emissivity of canopy in specific wavelengths and to extract vegetation indices [14-16]. The optical measurements obtained by remote sensing allow to estimate the agronomic variables of the cultivated species, describing the reciprocal relationships existing between solar radiation and vegetation [17]. There are many studies carried out to demonstrate the correlation between the vegetation indices and the experimentally measured agronomic variables [18-22]. The purpose of the vegetation indices is to compare the marked difference between the low reflectance in the in red and blue wavelength of the visible band caused by photosynthesis, and the high reflectance in the near infrared (NIR) due to the scattering processes within the foliar mesophyll. The Simple Ratio (SR) and the Normalized Difference Vegetation Index (NDVI) are the most used intrinsic indices that consider only the reflectance as variables.Considering the reflectance $\rho_{(N I R)}$ in NIR and $\rho_{(R E D)}$ in the red wavelength, SR is given by $\rho_{(N I R)} / \rho_{(R E D)}$, whereas NDVI is obtained through the expression $\left[\rho_{(N I R)}-\rho_{(R E D)}\right] /\left[\rho_{(N I R)}+\rho_{(R E D)}\right][23-25]$. The NDVI index is a simple indicator, which can be used to analyse the spectrum-radiometric data of any living plant species, compared to bare soil. Plants perceive PAR (Photosynthetically Active Radiation), absorbing in the visible spectrum the light energy useful for the photosynthetic process. Conversely, in NIR spectrum, solar radiation does not carry enough energy to allow the synthesis of organic molecules, therefore, the plants reflect it almost all. As a result, plant cells protect their photosynthetic systems 
from oxidative phenomena, dissipating excess heat (extra-PAR). Plants, in short, reflect little in the visible spectrum, more in NIR [26-28].

Furthermore, starting from the aforesaid spectre-radiometric data, instruments exist, which by means of suitable filters can distinguish the pixels occupied by the vegetation from the remaining ones allowing to evaluate the amount of the foliar coverage of soil also known as Top-Of-Canopy (TOC).

The aim of this paper is to study the maize crop health condition by means of the remote sensing technique using Unmanned Aerial Vehicles (UAV) through the study of the relation between NDVI and TOC.

\section{Materials and Methods}

\section{Field equipment}

The research wascarried out at a farm located in the Southern Italy (Lucera, Foggia) on a 4hectare flat land cultivated with a maize crop for grains(P0937-hybrid corn crop)placed on, as shown in Fig. 1a (the yellow line marks the boundaries of the field test).

Management of the agronomic inputs was the same for the whole surface. The irrigation system, however, divided the cultivation into two sectors (north and south), each of 2 ha.This plant allowed to supply water in rescue of the vegetation for a total of $2400 \mathrm{~m}^{3}$ of water, with a 3-day turn.On average, therefore, for both sectors, the daily water volumes per hectare distributed below the canopy were equal to $400 \mathrm{~m}^{3}$ ( $40 \mathrm{~mm}$ ), for a total of 10 supplies (Fig. 1b).
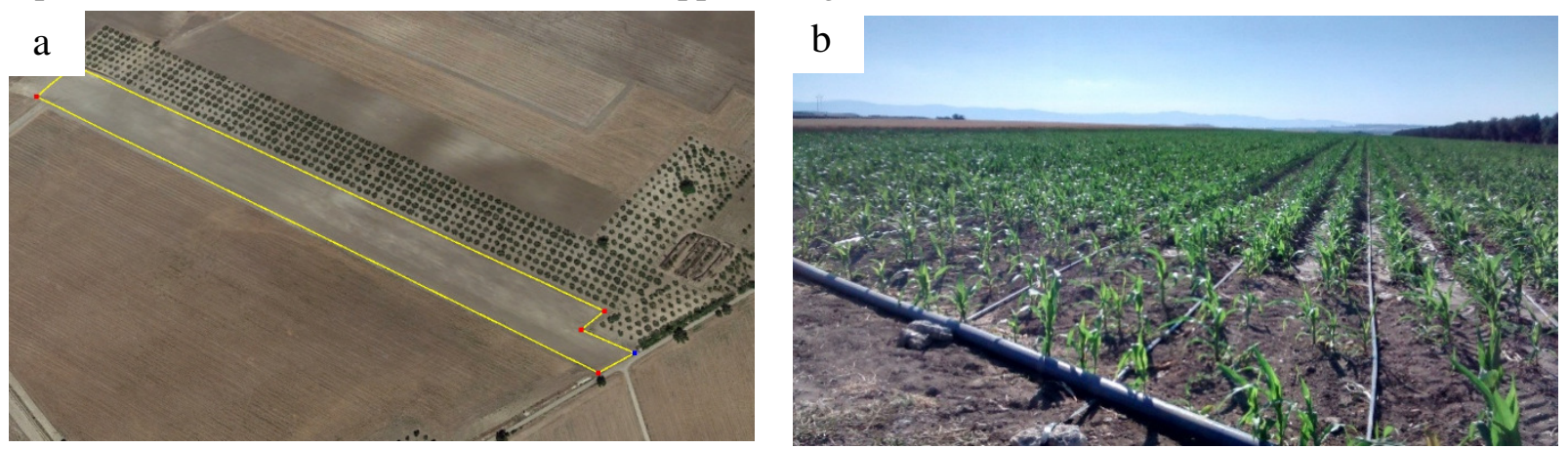

Fig. 1. Field test: a - Land cultivated with maize crop under test; b - Maize crop on 21 June 2018

\section{$U A V$, digital cameras and software employed}

Remote sensing was carried out using a quadcopter equipped with a vertical axis induction multirotor, belonging to the LASE category (Low Altitude Short Endurance). The UAV, with dimensions of $72 \times 72 \times 72 \mathrm{~cm}$ and mass around $7 \mathrm{~kg}$, was manoeuvred in order to perform shortduration flight missions and with a high accuracy of the surveys, compared to similar studies conducted in precision agriculture (Ground Sampling Distance-GSD 4cm/px).The UAV, at the time of the overflight, was simultaneously equipped with the following cameras: i) digital optical RGB YI Action Camera (Shanghai, China) fitted with a15Mpx image sensor; ii) multispectral optics ADC snap, which creates images with a resolution of 1280x1024 px(Tetracam Inc, Chatsworth, CA, USA); iii) thermal camera Flir Vue Pro Rfitted with an uncooled micro-bolometer as the thermal imager that allows resolution of 640x512 px and a spectral band within 7.5-13.5 $\mu \mathrm{m}$ (Flir System Inc., Wilsonville, OR, USA).

The multispectral camera used is fitted with a rectangular lens and a "Global Shutter" sensor, which allows to record at the same time the entire Ground Instantaneous Field of View (GIFoV)area framed by the sensor without distortion effects (motion blur, and other).The images acquired in the multispectral band are in the native format RWS. The software GPS-Distiller (Tetracam INC), later, converted in RAW format, suitable for post-processing carried out by means the PW2 (PixelWrench2, Tetracam INC) and Pix4D Mapper (Pix4D S.A., Switzerland) software.The drone followed a path specified by several waypoints with a speed of $4.8 \mathrm{~m} \cdot \mathrm{s}^{-1}$, acquiring images with a $70 \%$ overlap from a constant altitude of $70 \mathrm{~m}$. During the drone flight the average air temperature was $37^{\circ} \mathrm{C}$. 


\section{Image processing}

PW2 was used to: i) set the colour matrix useful for identification of the "vegetation pixels" (colour-processing function); ii) to attribute to each layer of the image file (24 bit depth) the correct $\lambda$ spectral band (NIR-790nm, Red-660nm, Green-550nm) and finally iii) convert RAW files to TIF format (Fig.2a). Using PW2 software were extracted data to evaluatethe NDVI and TOC variables that, with a statistical analysis (Student's $t$-test), allowed to detect areas with different vegetative growth.

Pix4D Mapper was then used for the construction of the DSM (Digital Surface Model) (Fig. 2b), resulted of the assembly of perfectly aligned mosaic units, which was used for computational calculation of the reflectance maps $\rho$ (NIR-790nm, Red-660nm) and for extraction of the NDVI vegetation index.

\section{Statistical analysis}

The stitching model in the multispectral band clearly highlights an area with reduced vegetative growth in the upper half of the south sector of the field, despite the management of the agronomic inputs being equal for the entire surface, as well as for the whole sector. This spatial variability was analysed through the statistical comparison of the NDVI data averages compared to those detected in the entire south sector. The objective was to understand whether the spatial variability recorded in the NDVI data of the stress area was due to chance ( $H_{0}=$ null hypothesis), or there was an external disturbance factor that caused the phenomenon $\left(H_{1}=\right.$ alternative hypothesis) $[29 ; 30]$. The agronomic inputs were applied equally on the entire surface (organic fertilization, mechanical processing, mineral fertilization, irrigation flow rate of $101 \cdot \mathrm{s}^{-1}$ at $0.1 \mathrm{MPa}$, no verified anomaly of the irrigation plant), so, with the proper precautions, the different physical-chemical composition of the soil is accepted as an alternative thesis.

\section{Results and discussion}

\section{Red and NIR reflectance map and scale}

Data processing allowed to build two maps of reflectance of the analysed maize cultivation related, respectively, to the Red and NIR radiation (Fig.2a and 2b). Post-processing results in a graphic model, in which each pixel is assigned a number in a scale of values, are highlighted by colour variable gradation.

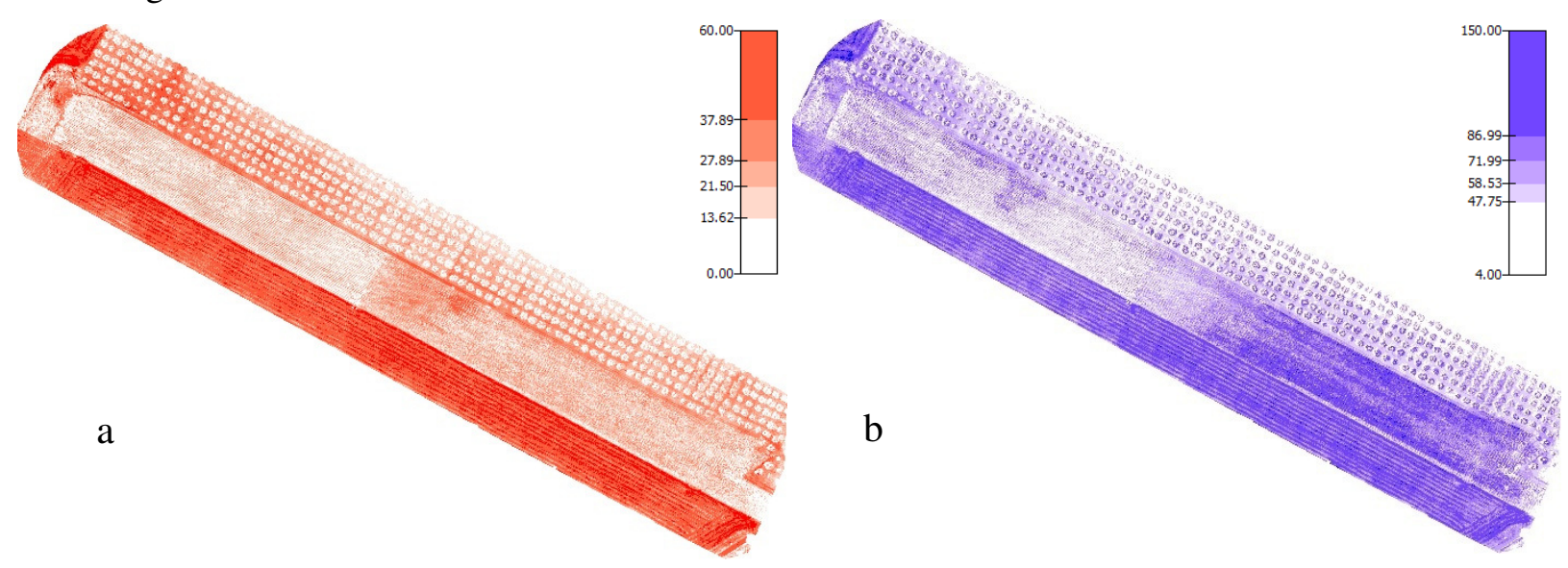

Fig. 2. Reflectance map and scale: $a-R e d ; b-N I R$

The red reflectance map, centred at the $660 \mathrm{~nm}$ band, shows reflectance gradients or inverting the reading scale of absorbance in the visible only relative to the south sector (Fig.2a). In this area, not completely homogeneous, the clearest pixels represent vegetation in good health and with a good level of development of the leaf apparatus compared to the soil (in red). This behaviour is due to the capacity of the plants to absorb almost completely the radiation in the Red, when they are in full vegetative activity, thus providing for the synthesis of organic molecules with photosynthesis. This consideration is realistic, because despite of the existence of a stressed area (central area), at the time 
of the surveys the soil of the field related to the south sector was in the process of drying up the irrigation water (Fig. 2a).

Conversely, the north sector was irrigated at the time of the overflight and seems able to absorb almost all the radiation in the Red (light pixels) even more uniformly than in the south sector. It must be said, however, that the conditions of hydration of the soil due to the presence of rainwater and/or irrigation, with the relative emission of steam, may affect the results of remote sensing, altering the optical readings and thus providing false data about the real conditions of vegetation.

Therefore, the result related to the north sector of the field is probably unrealistic, also because an inspection carried out on the location showed a more stunted growth of plants and a small number of leaves issued by plants. In this regard, the scientific works showed that the greater the absorbance of plantsin the Red spectrum, the more limited their development relative to the ability to produce biomass. Therefore, the influence of several combined factors, such as the soil moisture, evaporation of free waters produced by irrigation, the high air temperatures (temperature of $37^{\circ} \mathrm{C}$, at the altitude of $70 \mathrm{~m}$ ), makes complex the evaluation of the physiological state of watered culture.

The reflectance map in the NIR radiation is the result of the data processing produced by the multispectral sensor, calibrated at the $790 \mathrm{~nm}$ band (Fig. 2b). The model shows densely blue coloured areas, while other ones have almost completely lacking colour. It is possible to hypothesize that the coloured areas of the cultivation are affected by an intense activity of biosynthesis, such that at the achievement of luminous saturation in the leaves there is an equally intense reflection for NIR.

We can conclude that the plants concerning the north sector, at the beginning of the irrigation time, have average high absorbance values in the Red radiation (corresponding to the minimum levels of reflectance), and low in the NIR radiation, due to the vegetative standstill caused by the high temperatures of the air and water stress.Conversely, there are medium-high levels of reflectance in NIR at the end of the irrigation period in the south sector, probably due to the growth metabolism, to the increase of refractive light phenomena inside the aerial spaces of the foliar parenchyma, as a consequence of the greater cellular turgidity and gaseous exchanges with the outside.

The reflectance maps in the Red and in the NIR radiation allowed to calculate for each pixel the NDVI vegetation index formula attaining to the definitive DSM of the NDVI index of the cultivation.

\section{Statistical analysis}

The Student's t-test applied in the analysis of the averages of a sample in deficit with the ones concerning a regular development highlights a significant value of t both unilateral $(\alpha=0.05)$ and bilateral $(\alpha=0.10)$. Therefore, based on the statistical data obtained and the wide margin of reliability of the Student's t-test, the validity of the thesis in the object $\mathrm{H}_{1}$ is confirmed, that is the phenomenon is caused by an external disturbance factor. Concerning this, it is believed that in areas subject to physiological stress, excess in active limestone causes a localized increase in $\mathrm{pH}$, which makes the nutritional elements supplied with mineral fertilization unavailable. Furthermore, the combination with the clayey component of the soil, in some limited areas, would also cause an increase in the water requirement, unlike the remaining cultivated areas. Therefore, there is a spatial variability of the soil with a different fertility gradient in the various areas, which can significantly affect the production, reducing the profitability of the crop.

\section{Correlation NDVI-TOC}

The interpolation of the NDVI and TOC data is reported in Fig. 3. The function is logarithmic with a positive correlation coefficient $r=0.9345$ and linear regression $R^{2}=0.8732$.

This trend line, in describing the behaviour of the two variables, shows a more than proportional variation of the NDVI index in conditions of low canopy density; conversely, it is not very proportional (tending to asymptote) with higher coverage density.

The NDVI index seems to be able to provide more detailed information about the canopy structure only when this last one is vigorous. Therefore, according to this statement, probably it is appropriate to carry out surveys aimed at evaluation of the NDVI before the end of the vegetative stage of the crops, limit beyond which the saturation occurs. 


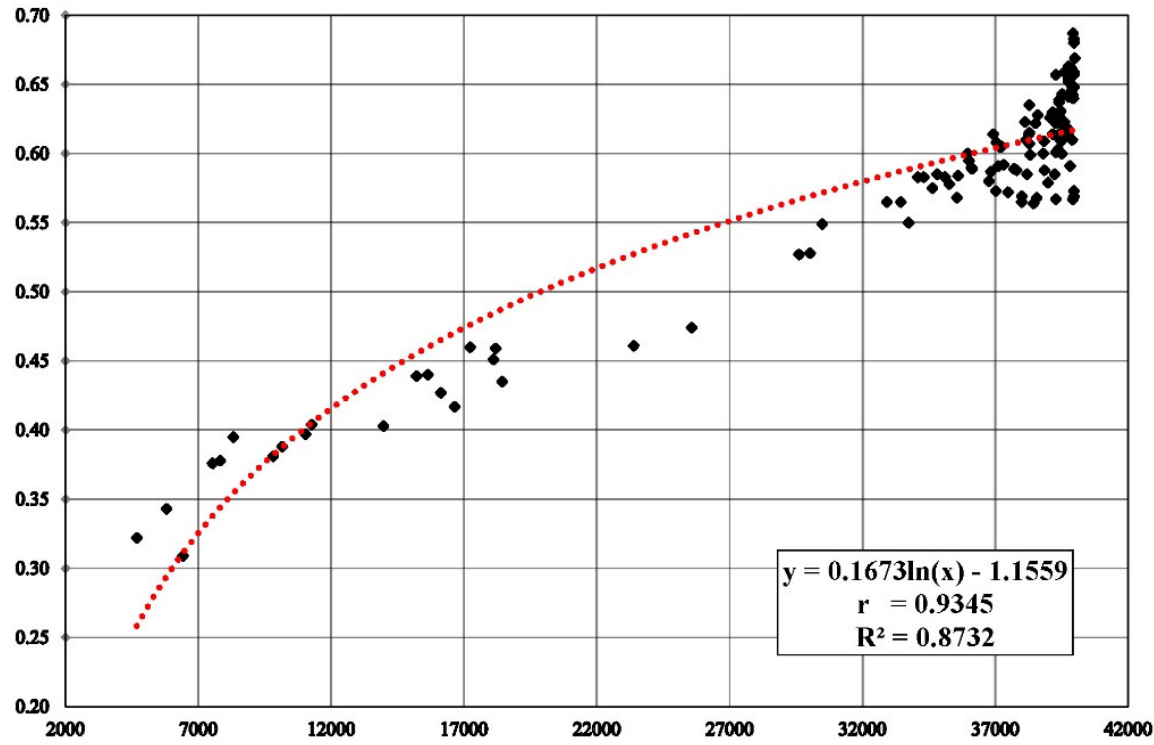

Fig. 3. NDVI - TOC correlation

\section{Conclusions}

1. Images were acquired by means of multi-spectral sensors arranged on a drone, which flew over the maize crop extending for 4.0 ha, which was divided into two sectors (north and south). Data processing allowed to analyse the reflectance of the cultivation related, respectively, to the Red and NIR radiation.

2. The plants concerning the north sector, at the beginning of the irrigation time, had average high absorbance values in the Red radiation (corresponding to the minimum levels of reflectance), and low in the NIR radiation, due to the vegetative standstill caused by the high temperatures of the air and water stress. Conversely, there are medium-high levels of reflectance in NIR at the end of the irrigation period in the south sector, probably due to the growth metabolism.

3. The statistical data analysis of NDVI and TOC highlighted that the zones with reduced vegetative growth could be due to an excess in active limestone that locally increasing in $\mathrm{pH}$ makes the nutritional elements supplied with mineral fertilization unavailable.

4. Analysing the correlation between NDVI and TOC seems that the NDVI index can provide more details about the canopy structure only when this last one is vigorous.

\section{Acknowledgements}

The authors equally contributed to the present study.

\section{References}

[1] Moran M. S., Inoue Y., Barnes, E. M. Opportunities and limitations for image-based remote sensing in precision crop management. Remote Sensing of Environment, vol. 61, 1997, 319-346.

[2] Baldoin C., Balsari P., Cerruto E., Pascuzzi S., Raffaelli M. Improvement in pesticide application on greenhouse crops: Results of a survey about greenhouse structures in Italy. Acta Hort. vol. 801, 2008, pp. 609-614.

[3] McBratney A. B., Whelan B. M., Shatar T. Variability and uncertainty in spatial, temporal and spatio-temporal crop yield and related data. In Precision agriculture: Spatial and temporal variability of environmental quality. Chichester: Wiley, 1997, pp. 141-160.

[4] Pascuzzi S., Santoro F. Analysis of Possible Noise Reduction Arrangements inside Olive Oil Mills: A Case Study. Agriculture 2017, 7(10), 88. DOI: 10.3390/agriculture7120100

[5] Santoro F., Anifantis A.S., Ruggiero G., Zavadsky V., Pascuzzi S. Lightning Protection Systems Suitable for Stables: A Case Study. Agriculture 2019, 9(4), 72. DOI: 10.3390/agriculture9040072

[6] Bacenetti J., Lovarelli D., Facchinetti D., Pessina D. An environmental comparison of techniques to reduce pollutants emissions related to agricultural tractors. Biosystems Engineering. Vol. 171, 2018, pp. 30-40. 
[7] Calcante, A., Facchinetti, D., Pessina, D. Analysis of hazardous emissions of hand-operated forestry machines fuelled with standard mix or alkylate gasoline. Croatian Journal of Forest Engineering. Vol. 39, Issue 1, 2018, pp. 109-116

[8] Brisco B., Brown R. J., Hirose T., Mcnairn H., Staenz K. Precision agriculture and the role of remote sensing: a review. Canadian Journal of Remote Sensing, vol. 24, 1998, pp. 315-327.

[9] Pascuzzi S. The effects of the forward speed and air volume of an air-assisted sprayer on spray deposition in "tendone" trained vineyards. J. Agr. Eng., vol. 3, 2013, pp.125-132. DOI: 10.4081/jae.2013.e18

[10]Cerruto, E., Manetto, G., Santoro, F., Pascuzzi S. Operator Dermal Exposure to Pesticides in Tomato and Strawberry Greenhouses from Hand-Held Sprayers. Sustainability 2018, 10(7), 2273, DOI: $10.3390 /$ su10072273

[11] Xiang H., Tian L. Method for automatic georeferencing aerial remote sensing (RS) images from an unmanned aerial vehicle (UAV) platform. Biosystems Engineering, vol.108, 2011, pp. 104-113.

[12] Pascuzzi S., Santoro F. 2015. Exposure of farm workers to electromagnetic radiation from cellular network radio base stations situated on rural agricultural land. International Journal of Occupational Safety and Ergonomics, Vol. 21, No. 3, 351-358. DOI: 10.1080/10803548.2015.1081774

[13] Seelan S. K., Laguette S., Casady G. M., Seielstad G. A. Remote sensing applications for precision agriculture: a learning community approach. Remote Sensing of Environment, vol. 88, 2003, pp.157-169.

[14]Zhang C., Kovacs J. M. The application of small aerial systems for precision agriculture: a review. Precision Agriculture, vol. 13, 2012, pp. 693-712.

[15] Lan Y., Thomson S. J., Huang Y., Hoffmann W. C., Zhang H. Current status and future directions of precision aerial application for site-specific crop management in the USA. Computers and Electronics in Agriculture, vol. 74, 2010, pp. 34-38.

[16] Vega F.A., Ramírez F.C., Saiz M.P., Rosúa F.O. Multi-temporal imaging using an unmanned aerial vehicle for monitoring a sunflower crop. Biosystems Engineering, vol. 132, 2015, 19-27.

[17] Pena-Barragan J. M., Lopez-Granados F., Jurado-Exposito M., Garcia-Torres L. Sunflower yield related to multitemporal aerial photography, land elevation and weed infestation. Precision Agriculture, vol. 11, 2010, pp. 568-585.

[18] Yang C., Bradford J. M., Wiegand C. L. Airborne multispectral imagery for mapping variable growing conditions and yields of cotton, grain sorghum, and corn. Transaction of ASAE, vol. 44, 2001, pp.1983-94.

[19]Berni J.A.J., Zarco-Tejada P.J., Suarez L., Fereres E. Thermal and narrowband multispectral remote sensing for vegetation monitoring from unmanned aerial vehicle. IEEE Transactions on Geoscience and Remote Sensing, vol. 47, 2009, pp. 722-738.

[20] Pascuzzi S., Blanco I., Anifantis A.S., ScarasciaMugnozza G. Hazards assessment and technical actions due to the production of pressured hydrogen within a pilot photovoltaic-electrolyzer-fuel cell power system for agricultural equipment. J. Ag. Eng., vol. XLVII:507, 2016, pp. 89-93

[21] Blanco I., Anifantis A.S., Pascuzzi S., ScarasciaMugnozza G. Hydrogen and renewable energy sources integrated system for greenhouse heating. J. Agric. Eng., 44,e45, 2013, 226230.DOI:10.4081/jae.2013.(s1):e4

[22] AnifantisA.S., Colantoni A., Pascuzzi S., Santoro F. Photovoltaic and Hydrogen Plant Integrated with a Gas Heat Pump for Greenhouse Heating: A Mathematical Study. Sustainability vol. 10(2), 2018, 378 - DOI: 10.3390/su10020378

[23] Corcoles J.I., Ortega J.F., Hernandez D., Moreno M.A. Estimation of leaf area index in onion (Allium cepa L.) using an unmanned aerial vehicle. Biosystems Engineering, vol. 115, 2013, pp. 31-42.

[24] Baluja J., Diago M.P., Balda P., Zorer R., Meggio F., Morales F., Tardaguila J. Assessment of vineyard water status variability by thermal and multispectral imagery using an unmanned aerial vehicle (UAV). Irrigation Science, vol. 30, 2012, pp.511-522.

[25] Manetto G., Cerruto E., Pascuzzi S., Santoro F. Improvements in citrus packing lines to reduce the mechanical damage to fruit. Chem. Eng. Trans. 58, 2017, pp. 391-396. DOI: 10.3303/CET1758066 
[26] Garcia-Ruiz F., Sankaran S., Maja J. M., Lee W. S., Rasmussen J., \&Ehsani R. Comparison of two aerial imaging platforms for identification of Huanglongbing-infected citrus trees. Computers and Electronics in Agriculture, vol. 91, 2013, pp.106-115.

[27]Zarco-Tejada P. J., Ustin S. L., Whiting M. L. Temporal and spatial relationships between withinfield yield variability in cotton and high-spatial hyperspectral remote sensing imagery. Agronomy Journal, 97, 2005, pp. 641-653.

[28] Pascuzzi S., Anifantis A.S., Cimino V., Santoro F. Unmanned aerial vehicle used for remote sensing on an Apulian farm in southern Italy. Engineering for Rural Development 17, pp. 149-154. DOI: 10.22616/ERDev2018.17.N175

[29]R Core Team. R: A language and environment for statistical computing. R Foundation for Statistical Computing, 2012, Vienna, Austria. ISBN 3-900051-07-0

[30] Forsythe G.F., Malcolm M.A., Moler C.B. Computer methods for mathematical calculations. Prentice Hall Professional Technical Reference, 1977. ISBN:0131653326 